\title{
13 The importance of sex- disaggregated and gender data to a gender-inclusive COVID-19 response in the aquatic food systems
}

\author{
Afrina Choudhury, Surendran \\ Rajaratnam, and Cynthia McDougall
}

Sex-disaggregated data and gender data are central to making informed policy and development program decisions for people reliant on the fisheries and aquaculture sector. Data collected and analyzed separately on males and females can be defined as sex-disaggregated data (Doss and Kieran 2014). In addition to collection and presentation of data by sex, gender data also reflects gender issues, is based on concepts and definitions that consider the diversity of women and men and all aspects of their lives, and is developed through collection methods that take into account stereotypes and social and cultural factors that may induce bias in data (United Nations Department of Economic and Social Affairs, 2016). Although sex-disaggregated data provides basic information by sex, policies and programs need gender data - including about barriers - in order to be inclusive and effective. Despite their significance, sex-disaggregated data (SDD) and gender data (GD) are not systematically collected and are lacking worldwide. This was problematic before COVID-19 and has been exacerbated with the onset of the global pandemic. Governments, as well as development and civil society organizations, are working to tackle the disastrous economic and social repercussions of the pandemic and its restrictions. Yet, these efforts are - often unknowingly - undermined by the lack of recognition and data about gender barriers and the different needs, resilience, and relative risks to people of all genders. Persistent gender data gaps, in other words, limit understanding about gendered differences - and the intersecting factors of poverty, caste, ethnicity, legal, or other status such as lack of legal citizenship. This limitation, in turn, significantly undermines the ability of policy and programming to work for the people who need it the most.

This challenge is critical in the fisheries and aquaculture sectors, notably in relation to understanding and responding to the gendered and diverse 


\section{0}

Afrina Choudhury et al.

needs of small-scale and informal fishers, processors, and retailers. Women play major roles in, and make significant contributions to, the fisheries and aquaculture sector worldwide, but these mostly remain unrecognized, from individual households to the scale of policy. The lack of recognition includes the fact that women's contributions are often reframed as "supporting roles" to "men's work" in a sector that is seen as a male domain (Kleiber et al. 2015; Harper et al. 2020). In this chapter, we explore the need for sexdisaggregated and gender data through examples from the highly fisheries and aquaculture-dependent contexts of India and Bangladesh. In particular, we present COVID-19-related challenges and responses that have gendered implications and highlight the importance of sex-disaggregated data and gender data to understand and cushion the (intersectionally) gendered impacts of the pandemic in the fisheries and aquaculture.

\section{Insights from Bangladesh and India}

In Bangladesh, despite the perception of the sector as a male domain, almost 80 percent of the workforce in fish and shrimp processing factories and drying sites are women and young children (Belton et al. 2014). However, these women are predominantly employed in low-level positions, with lowincome and inadequate safety standards and hygiene in place (Choudhury et al. 2017). When COVID-19 hit Bangladesh, the lockdown issued by the government drastically reduced orders, fish landings, and supplies in general. Most of these plants and drying sites either shut down or significantly reduced operations, leaving thousands of women workers jobless and with few alternatives.

Furthermore, return migration of men from the city and other regions (as a result of job loss) added extra pressure on the fishing labor market in Bangladesh. Increasing numbers of men are thus now engaging in areas on which women relied for their livelihoods pre-pandemic, such as shorebased fishing and gleaning resulting in reduced catches for these women fishers. The lack of livelihood opportunities for women, and threats to existing ones, led women to use their existing stocks of dried fish, thereby depleting their source of income and food without being able to replace it. Even with a decrease in fish prices in the market, many women could not afford to purchase fish because they could not generate the required income during the initial period of the pandemic. To combat livelihood losses, the Government of Bangladesh has continued to issue rations to registered fishers - "registered" being the key word here. Women in Bangladesh are not recognized as fishers, and thus not registered as fishers. As a consequence, women are therefore unable to access these rations. Unfortunately, policy definitions of "fishers" exclude people involved in post-harvest parts of the 
value chain as well as those involved in gleaning, which is where women are primarily involved. Therefore, dry-fish producers (including women), laborers in processing plants and drying sites (mostly women), have no "fisher" identification cards, hence they do not get the needed support from the government. The narrow and arguably gendered definition in the sector results in this COVID-19 social protection measure being inaccessible to many people who need it the most.

In Assam, India, a study we conducted in communities reliant on pond aquaculture and beel (floodplain wetlands) fisheries found women taking primary responsibility for reproductive activities such as food preparation. In some communities they are also involved in dry- and fermented fish production. At the same time, however, members of the household (including women) conform to inequitable gender norms regarding intra-household food distribution. Women tend to eat only after serving other family members. Their reproductive work is unpaid and little recognized or valued (even when it contributes to household income). The initial state-wide COVID-19 lockdown imposed by the government that affected the income and food supply of households was worst for poor households who do not have adequate amounts of food stocked. Women in this lower socioeconomic group and families are likely to be especially heavily impacted by this inadequacy and the low quality of food given the pre-existing inequitable norms. Even with food assistance given by government and non-government agencies, failure to understand and address gendered intra-household food allocation can cause the deterioration of women's nutrition and health. Moreover, this has intergenerational consequences: undermining the nutrition of women of reproduction age directly undermines nutrition essential in the first 1,000 days of life, affecting the development of unborn children and infants.

In the state of Odisha, a key entry point for many women in (otherwise male-dominated) aquaculture production is through state-sponsored women's groups. These groups aim to contribute to women's economic empowerment through fish production and marketing. COVID-19, however, led to members being unable to purchase fish feed and other pond maintenance products due to restrictions in transportation/mobility and the closure of shops. Fingerlings were not available at the right time; therefore the stocking of the fingerlings was affected/delayed. The women's groups also faced challenges to harvesting fish from their fish ponds due to unavailability of men to do the work (a constraint that highlights the continuing strongly gendered norms and division of labor in this context). The groups were also less able to market the fish due to restrictions in transportation/mobility. An additional insight from Odisha is that although both women and men access reservoirs to fish, and the challenges faced by women and men fishers were reported to be similar, women cope with the economic impact of COVID-19 
in a way that men did not. Specifically, women utilized their home gardens to plant and cultivate vegetables. This helped to reduce their purchase of vegetables from the market, which had increased in price, thus keeping their expenses low. Women also expanded on their small home-based businesses during COVID-19, including marketing homemade snacks such as papads and pickles as well as making fabric face masks for local sale.

Similar to the situation in Bangladesh, the return migration of men who left to work in the city or other states impacted the livelihoods of resident women and men in their communities in India. Although the return of (now unemployed) young men in aquaculture and fisheries may create new opportunities, it may also displace women and less powerful men who are barely surviving the economic challenges brought by the pandemic. Even with cross-state borders opening again, the number of men migrating out of Assam's fishing communities again to work is reported to be less than previously. This could mean that competition for work within the fishing community work may continue to be higher than pre-pandemic.

In both Assam and Odisha, as with many other contexts, women are heavily dependent on the post-harvest part of fish value chains and so were particularly affected by changes in markets. In Assam, women who earn income as fish processors reported being affected by lockdown and movement restrictions. These COVID-19 controls also affected women who relied on fish pickle and fermented fish production, because of the downturn on special events and celebrations. Women's income from fish drying was also affected as these products couldn't be sent to neighboring states, which is its normal market. In Odisha, women selling fish from their homestead ponds reported that the price of fish went down during the initial phase of travel restrictions as these fish were unable to be sold in the market. Similarly, women selling fish at farm gate reported a 25 percent drop in volume.

\section{The need for sex-disaggregated and gender data}

Despite the aquatic food sector being considered a male domain (a perception due in part to the lack of sex-disaggregated and gender data), women as well as men depend on and contribute to the sector. However, as illustrated in this chapter, they may be affected differently by shocks. This underscores the need to make informed policy and development program decisions based on sex-disaggregated data and gender data for the sector to thrive and benefit women and men equally. In conjunction with this, policy, development, private sector and research actors need to rethink "what counts" as fisheries - directly affecting "who is counted." Women's engagement in, their contributions to, and the gender barriers that persist in the fisheries and aquaculture 
sector need to be identified, measured, and addressed in government and nongovernment responses. This is imperative now in relation to the COVID-19 pandemic and also in relation to climate change and future shocks as well.

In this complex time, WorldFish and partners have conducted a range of studies to understand the impacts of COVID-19 on the fisheries and aquaculture sector. With the large number of unrecognized, unreported women working in the lower and informal rungs of aquatic foods chains or in small-scale production, we found that even getting teams to effectively sample and engage equally and representatively with women has proven to be challenging. Even women business owners and entrepreneurs who are working in the sector, and women who play key roles in small (household) businesses, remain un- or under-recognized and reported, and thus underrepresented in insights from research. This is compounded by the increased work burdens women are facing in many contexts. Moreover, due to gendered access to phones and constraining norms, COVID-19 pandemic's social distancing guidelines and resultant phone interviews mean that women's inputs may be further at a risk unless special measures are taken. To try to counter these risks, WorldFish, together with ACIAR, produced tips on gender integration in research during COVID-19 (see McDougall and Curnow 2020). WorldFish also generated a guidance note on research quality during distance research that explicitly recognizes gender integration as central to quality (McDougall et al. 2020).

Given the high populations and population densities in India and Bangladesh, the multiple challenges people face in accessing and benefiting from the health care services, the loss of livelihood and income and many other challenges the disease brought to the countries, the impact of COVID19 may be far worse than what is being reported. These impacts are gendered, with women and girls bearing the brunt and often not receiving the needed support to overcome the challenges brought by the pandemic. With persisting gender gaps in access to inputs and resources already, we need to take extra precautions to ensure the COVID-19 response is at a minimum gender-responsive, if not transformative (see McDougall et al. 2015). Gender data gaps lead to gender-blind policies and frameworks, but also to implementation of responses to shocks that may exclude women from the safety nets, support, and investments that are much needed for an inclusive recovery and for building forward better.

\section{Continuing our work given COVID-19 restrictions and risks}

\section{Surendran Rajaratnam}

When the threats of the COVID-19 pandemic were announced by the Malaysian government in early 2020, we prepared to work from home for 


\section{Afrina Choudhury et al.}

a short period of time initially. Little did I know that the temporary change would still remain, a year later. Having to change the way I work was challenging in the beginning as I try not to bring work back home. However, over the past year, I managed to adapt to this new work arrangement. An amount of field work planned in India early last year couldn't be conducted due to the travel restrictions. One plan for a study was changed to a deskbased study as we couldn't foresee the end of the travel restrictions last year. Studies which were able to be conducted remotely continued with the support of field-based staffs and partners. These were conducted by following the country's procedures and taking precautions to ensure that our work doesn't risk the staff as well as people in the community.

\section{Cynthia McDougall}

In terms of field work, the major adaptation to COVID-19 was about shifting to virtual methods. While this posed challenges, it has also pushed us to be creative - such as teams and participants figuring out how to use WhatsApp to share inputs. One positive aspect for which I am grateful is that the challenges also created opportunities for transdisciplinary partnerships that had not existed previously. In a sense, we partners found each other through the need to rapidly learn and share lessons about what works for different women and men in these incredibly difficult times. At a personal level, the family all working and schooling from home in Penang, Malaysia, took some adjustments, but I would not trade that time together for anything. It has been an important prompt to reassess work-life balance and quality of life.

\section{Afrina Choudhury}

During the COVID-19 outbreak in early 2020, I was in the Wageningen University \& Research (WUR) as a PhD student. As my PhD study is partially funded by WorldFish, I also spend a few hours every week managing some of the projects of the organization in Bangladesh. I was lucky to be able to board the last flight out of Amsterdam to Vancouver to join my husband as the preparation for state-wide lockdown was in place. I have been working from home since then, attending classes online, completing assignments. I have been managing these responsibilities on top of my pregnancy, childbirth, and childcare.

\section{Acknowledgments}

This work was undertaken as part of the CGIAR Research Program on Fish Agri-Food Systems (FISH) led by WorldFish. The program is supported 
by contributors to the CGIAR trust fund. The chapter benefited from data provided by WorldFish and partners in Odisha and Assam, India, and in Bangladesh.

\section{References}

Belton, B., Hossain, A.R.M., Rahman, M. \& Thilsted, S.H., 2014. Dried -fish production, consumption and trade in Bangladesh. In: S.H. Thilsted \& M.A. Wahab, eds. World Bank/SAFANSI Funded Regional Workshop on Small Fish and Nutrition, 1-2 March, 2014 Dhaka.

Bennett, N.J., et al., 2020. The COVID-19 pandemic, small-scale fisheries and coastal fishing communities. Coastal Management, 48(4), 336-347.

Choudhury, A., McDougall, C., Rajaratnam, S. \& Park, C.M.Y., 2017. Women's Empowerment in Aquaculture: Two Case Studies from Bangladesh. Rome: Food and Agriculture Organisation of the United Nations; Penang: WorldFish.

Doss, C. \& Kieran, C. 2014. Three things you need to know about sex-disaggregated data. Available from: https://a4nh.cgiar.org/2014/05/05/three-things-you-need -to-know-about-sex-disaggregated-data/

Harper, S., et al., 2020. Valuing invisible catches: Estimating the global contribution by women to small-scale marine capture fisheries production. PLoS ONE, 15(3), $1-16$.

Kleiber, D., Harris, L.M. \& Vincent, A.C., 2015. Gender and small-scale fisheries: A case for counting women and beyond. Fish and Fisheries, 16(4), 547-562.

McDougall, C. \& Curnow, J., 2020. Safeguarding gender integration in research during the COVID-19 pandemic. Retrieved from https://pim.cgiar.org/2020 /05/29/safeguarding-gender-integration-in-research-during-the-covid-19 -pandemic/

McDougall, C., et al., 2015. Implementing a gender transformative research approach: early lessons. In: CRP AAS. Research in Development: Learning from the CGIAR Research Program on Aquatic Agricultural Systems. Penang: WorldFish.

McDougall, C., et al., 2020. Ten strategies for research quality in distance research during COVID-19 and future food system shocks.

United Nations Department of Economic and Social Affairs, 2016. Integrating a gender perspective into statistics. Studies in Methods, Series F No.111. Available from https://unstats.un.org/unsd/demographic-social/Standards-and-Methods/ files/Handbooks/gender/Integrating-a-Gender-Perspective-into-Statistics-E.pdf 